\title{
A influência das affordances no posicionamento das mãos para abertura de embalagens de água mineral
}

\section{The influence of affordances on the positioning of hands to open mineral water packages}

Gabriel Henrique Cruz Bonfim, Universidade Federal de Uberlândia.

gabriel.bonfim@ufu.br

Fernando José Carneiro Moreira da Silva, Universidade de Lisboa.

fms.fautl@gmail.com

Luis Carlos Paschoarelli, Universidade Estadual Paulista.

luis.paschoarelli@unesp.br

\section{Resumo}

A análise de affordances é um componente importante para a investigação de tarefas motoras que envolvem a manipulação de produtos. O presente estudo teve como propósito verificar como se dá o posicionamento das mãos durante a abertura de embalagens com diferentes formatos e como essa ação é influenciada pelas affordances. Participaram 240 brasileiros e portugueses igualmente divididos entre jovens, adultos e seniores. Foram avaliadas 5 embalagens no Brasil e 5 embalagens em Portugal, com características morfológicas semelhantes. A tarefa realizada foi pegar e abrir cada uma das embalagens. Ao final, não houve diferenciação entre os dois países nem entre os gêneros. Os fatores para o posicionamento das mãos foram o centro de massa e a forma do produto. Regiões côncavas auxiliam a manipulação, porém quando estas estão abaixo do centro da embalagem transmitem a ideia de desequilíbrio e dificulta a percepção das melhores affordances.

Palavras-chave: Embalagens, Affordances, Preensão

\begin{abstract}
The analysis of affordances is an important component for the investigation of motor tasks involving the manipulation of products. The purpose of the present study was to verify how hand placement occurs during the opening of packages with different shapes and how this action is influenced by affordances. Participated 240 Brazilian and Portuguese subjects equally divided among youth, adults and seniors. Five packages were evaluated in Brazil and 5 packages in Portugal, with similar morphological characteristics. The task subjects had to accomplish was to grab and open each package. There was no differentiation between the two countries or between genders. The factors for the positioning of the hands were the center of mass and product shape. Concave regions help manipulation, but when they are below the center of the packaging they convey the idea of imbalance and make it difficult to perceive better affordances.
\end{abstract}

Keywords: Packages, Affordances, Prehension 


\section{Introdução}

Antes de pegar um objeto, a mão assume uma conformação não somente de acordo com as propriedades do objeto, como tamanho e forma (JEANNEROD, 1981; MASON et al., 2001; SANTELLO; SOECHTING, 1998), mas também depende de como este objeto será manipulado para completude da tarefa (ANSUINI et al., 2006, 2008). Por exemplo, atividades como agarrar, levantar, despejar e até mesmo arremessar, determinam a conformação da mão, bem como as estratégias biomecânicas e cinesiológicas adotadas pelo usuário, para utilizar aquele objeto. Além disso, a escolha do posicionamento da mão no objeto também vai de acordo com as demandas de tarefas subsequentes. De acordo com Cohen e Resenbaum (2004), em um estudo no qual participantes seguravam um objeto cilíndrico e moviam para uma nova posição, foi constatado que havia uma relação inversa entre a altura da preensão no objeto cilíndrico e altura da posição para onde era movido. Portanto, o movimento que o indivíduo planeja realizar, influencia no posicionamento das mãos ao segurar um objeto.

Outros estudos também analisaram a relação entre o tamanho do objeto e as formas de preensão (CASTIELLO, 1996; PAULIGNAN et al., 1997; CASTIELLO, 1999; SMEETS; BRENNER, 1999), além de outras propriedades, como fragilidade (SAVELSBERGH et al., 1996), tamanho da superfície de contato (BOOTSMA et al., 1994), textura (WEIR et al., 1991a) e peso (WEIR et al., 1991b; JOHANSSON; WESTLING, 1988; GORDON et al., 1991). Sabe-se que todos esses fatores exercem influência sobre a manipulação de um objeto. Por exemplo, é necessário haver mais precisão e maior aderência ao segurar objetos mais pesados do que objetos mais leves, portanto o peso de um objeto limita o posicionamento dos dedos (SMEETS; BRENNER, 1999). A preensão exigida no início do movimento, para segurar objetos escorregadios, é maior em comparação com objetos de superfície áspera. No entanto, na maioria desses casos, os participantes foram solicitados a usar um tipo de preensão, sem considerar o tamanho ou a forma do objeto.

Sartori et al. (2011) analisaram a manipulação de uma embalagem totalmente cilíndrica e de uma embalagem com uma região côncava (então denominada 'cintura'). Os autores apontam que, independentemente das restrições de precisão, o objetivo final da ação é facilitado pela affordance do objeto. Além disso, o posicionamento dos dedos no objeto se da pela forma das embalagens e pelo objetivo final da ação.

O que ainda não se sabe é como diferentes formatos de embalagens com tampa de rosca influenciam o posicionamento das mãos durante a abertura de tais objetos. Esta é uma questão ligada à noção de affordances formulada pela primeira vez por Gibson $(1977,2015)$.

O conceito de affordance refere-se às propriedades de uma superfície ou de um objeto no ambiente, que potencializam dentro de um observador, possibilidades de ações específicas sobre ele. No entanto, uma affordance não depende da presença de um observador para que possa existir, pois ela implica em tudo o que o ambiente oferece, e não apenas o que o indivíduo consegue observar (MICHAELS, 2003; REED, 1988). Além disso, nem sempre a percepção de uma affordance significa que ela será efetivada (REED, 1988). Para que uma affordance seja percebida é necessário que o indivíduo possua propriedades que o possibilitem perceber e fazer uso da affordance (TURVEY et al., 1981). 
De acordo com Gibson (1977, 2015), um indivíduo pode ou não perceber affordances, segundo suas necessidades. Portanto, affordances são oportunidades, independentemente se o agente irá utilizá-las ou não. Ainda que um macaco esteja dormindo, uma banana continuará sendo comestível; ou mesmo que uma pessoa não seja agressiva, um bastão continuará sendo uma arma (LOMBARDO, 1987).

Seguindo esta visão, estudos comportamentais e neurofisiológicos demonstram que a simples observação de um objeto envolve o acesso a programas motores para interação com o objeto, mesmo na ausência de intenções explícitas de ação. Mais especificamente, foi demonstrado que características pragmáticas de um objeto acionam automaticamente componentes de ações específicas, como alcançar ou segurar (CRAIGHERO et al., 1999; ELLIS; TUCKER, 2000; PHILLIPS; WARD, 2002; TUCKER; ELLIS, 1998, 2001, 2004).

Embora affordances tenham sido estudadas no contexto da configuração da mão para segurar um objeto (MON-WILLIAMS; BINGHAM, 2011; LEDERMAN; WING, 2003; BAUD-BOVY; SOECHTING, 2001; MARK et al., 1997), ainda existem questionamentos sobre como elas contribuem para o objetivo final da ação e/ou como diferentes formatos de um mesmo objeto influenciam o posicionamento das mãos para realizar a preensão. Além disso, ajudar a esclarecer esses questionamentos pode ser um contributo expressivo para os estudos sobre interfaces físicas e o Design de Produtos.

Portanto, o objetivo do presente estudo foi verificar como se dá o posicionamento das mãos durante a abertura de embalagens de água mineral com diferentes formatos e como essa ação é influenciada pela percepção de affordances.

\section{Materiais e métodos}

O presente estudo realizou uma abordagem de caráter experimental e transversal, caracterizado por simulação de uso do objeto de estudo, por usuários e consumidores habituais.

\section{Questões éticas}

Por se tratar de um estudo que envolve seres humanos, o protocolo de pesquisa foi submetido e aprovado pelo Comitê de Ética em Pesquisa da Faculdade de Arquitetura, Artes, Comunicação e Design - UNESP, atendendo a Resolução 466/12-CNS-MS e o "Código de Deontologia do Ergonomista Certificado" (ABERGO, 2003).

Também foi aplicado um Termo de Consentimento Livre e Esclarecido (TCLE), o qual referese a um documento que informa os procedimentos, materiais e objetivos do estudo, bem como esclarece que os riscos são mínimos e a identidade do participante é preservada, sendo os resultados divulgados no meio científico e acadêmico de forma anônima e global. 


\section{Amostra}

A definição da amostragem baseou-se na teoria da inferência estatística (CASELLA; BERGER, 2010), na qual é analisado o conjunto de dados de um determinado conjunto amostral, para apresentar projeções aceitáveis para uma população. Portanto, o estudo contou com 240 participantes, sendo 120 brasileiros e 120 portugueses; todos igualmente distribuídos nas faixas de jovens (18 a 29 anos - 40 homens e 40 mulheres); adultos ( 30 a 55 anos - 40 homens e 40 mulheres); e seniores (55 a 75 anos - 40 homens e 40 mulheres). Foi considerado como fator de exclusão, para a não participação no estudo, a incapacidade do indivíduo em abrir as embalagens escolhidas para o teste.

\section{Variáveis do estudo}

No presente estudo, foram caracterizadas como variáveis independentes: o gênero dos participantes (masculino e feminino); as faixas etárias (jovens, adultos e idosos) e as diferentes embalagens de água mineral. A variável dependente foi caracterizada pelas affordances adotadas pelos usuários, ou seja, os posicionamentos das mãos nas embalagens durante o ato de preensão (KAPANDJI, 2007) exigido para o processo de abertura. Para as embalagens "sem cintura" (B1, B2, P1 e P2), as posições das preensões foram "superior", "centro-superior", "central", "centro inferior" e "inferior" (Figura 01). Para as embalagens "com cintura" (B3, B4, B5, P3, P4 e P5), as posições das preensões foram "sem apoio na cintura"; "apoio do dedo mínimo na cintura"; "apoio do dedo médio na cintura"; "apoio do dedo anelar na cintura" e "apoio do dedo mínimo na cintura" (Figura 02). Considerou-se como "cintura", a região côncava que circunda a embalagem em determinada altura.

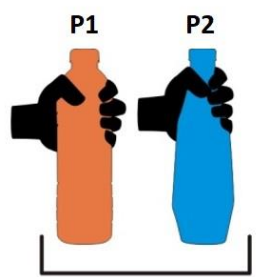

SUPERIOR

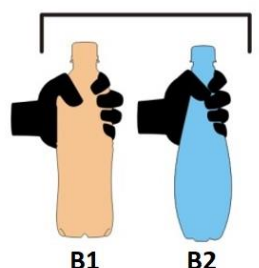

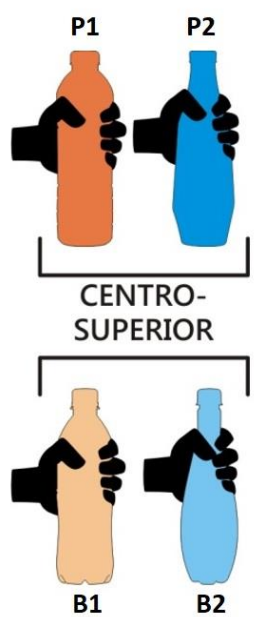

B2

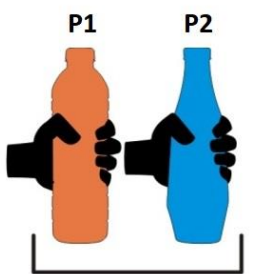

CENTRAL

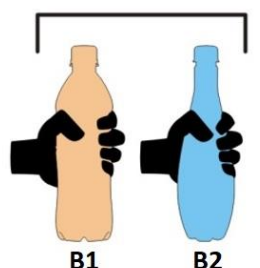

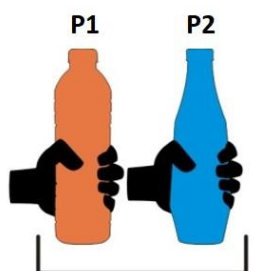

CENTROINFERIOR

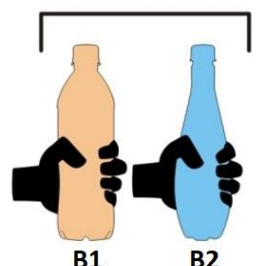

(n) 


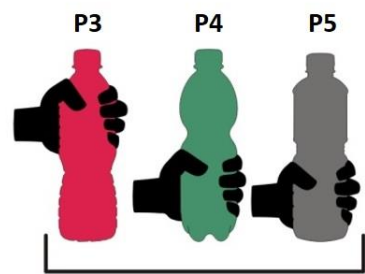

SEM APOIO NA CINTURA

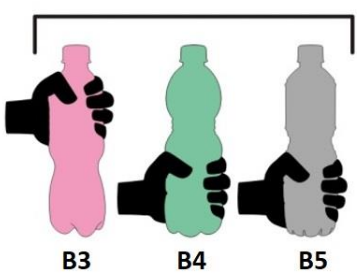

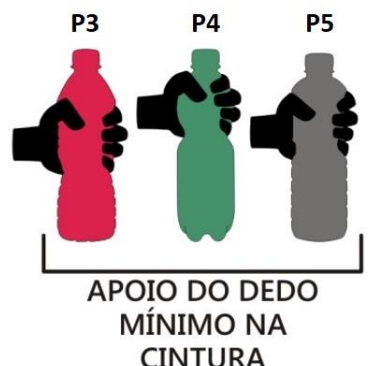

CINTURA

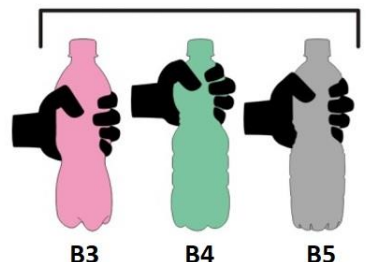

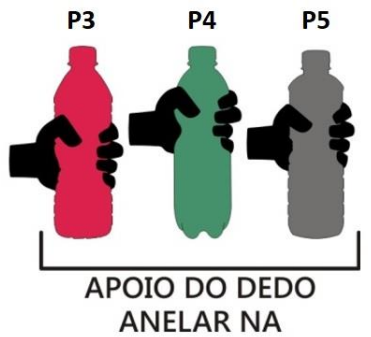

CINTURA

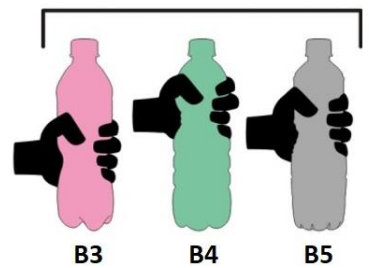

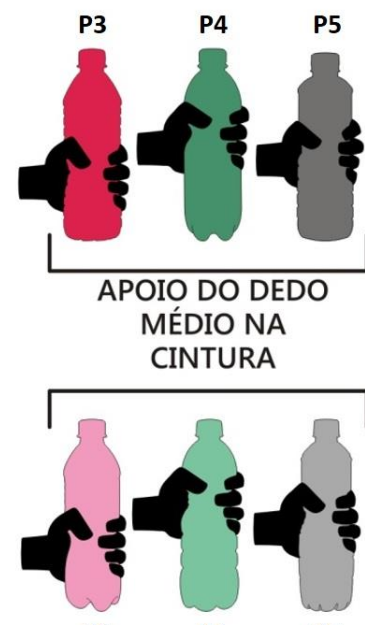

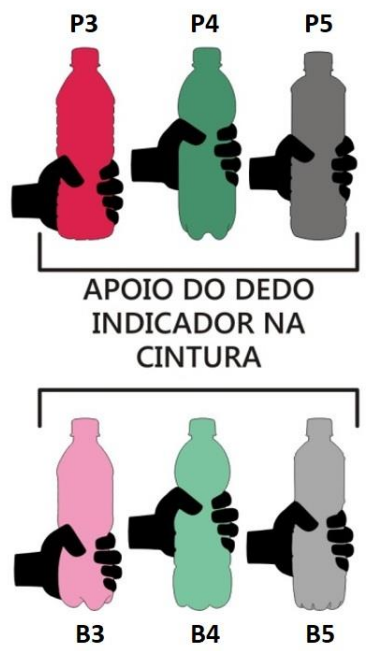

Figura 02: Affordances observadas nas embalagens com cintura (P3, P4, P4, B3, B4 e B5)

\section{Materiais}

Entre os materiais utilizados e suas finalidades destacam-se:

- Protocolo de Identificação. Este protocolo serviu para coleta de dados de identificação do sujeito como: nome, idade, gênero, lateralidade, grau de instrução, sintomas musculoesqueléticos nos membros superiores;

- Embalagens de Água Mineral. A seleção de tais embalagens se deu com base na oferta de comercialização das mesmas nas diferentes regiões do estudo (Bauru-Brasil e LisboaPortugal), prezando os diferentes designs e características como rugosidades, forma, ausência ou presença de "cintura". Dessa forma, no Brasil, foram escolhidas cinco (05) embalagens PET (Figura 03), das quais foram retirados os rótulos, visando eliminar quaisquer elementos que pudessem chamar a atenção do usuário, senão a forma da embalagem. Outras cinco (05) embalagens foram selecionadas em Portugal (Figura 04), as quais possuíam características semelhantes àquelas do Brasil, delas também foram 
retirados os rótulos. Portanto, foram selecionadas: uma embalagem sem cintura destacada (B1 e P1); uma embalagem com formato chamativo, diferente do padrão encontrado no mercado (formato de gota no Brasil - B2 e formato de diamante em Portugal - P2); uma embalagem com cintura na parte inferior (B3 e P3); uma embalagem com cintura na parte superior (B4 e P4) e uma embalagem com cintura na parte central (B5 e P5). Cabe ressaltar que todas as embalagens selecionadas possuíam o volume de $500 \mathrm{ml}$.
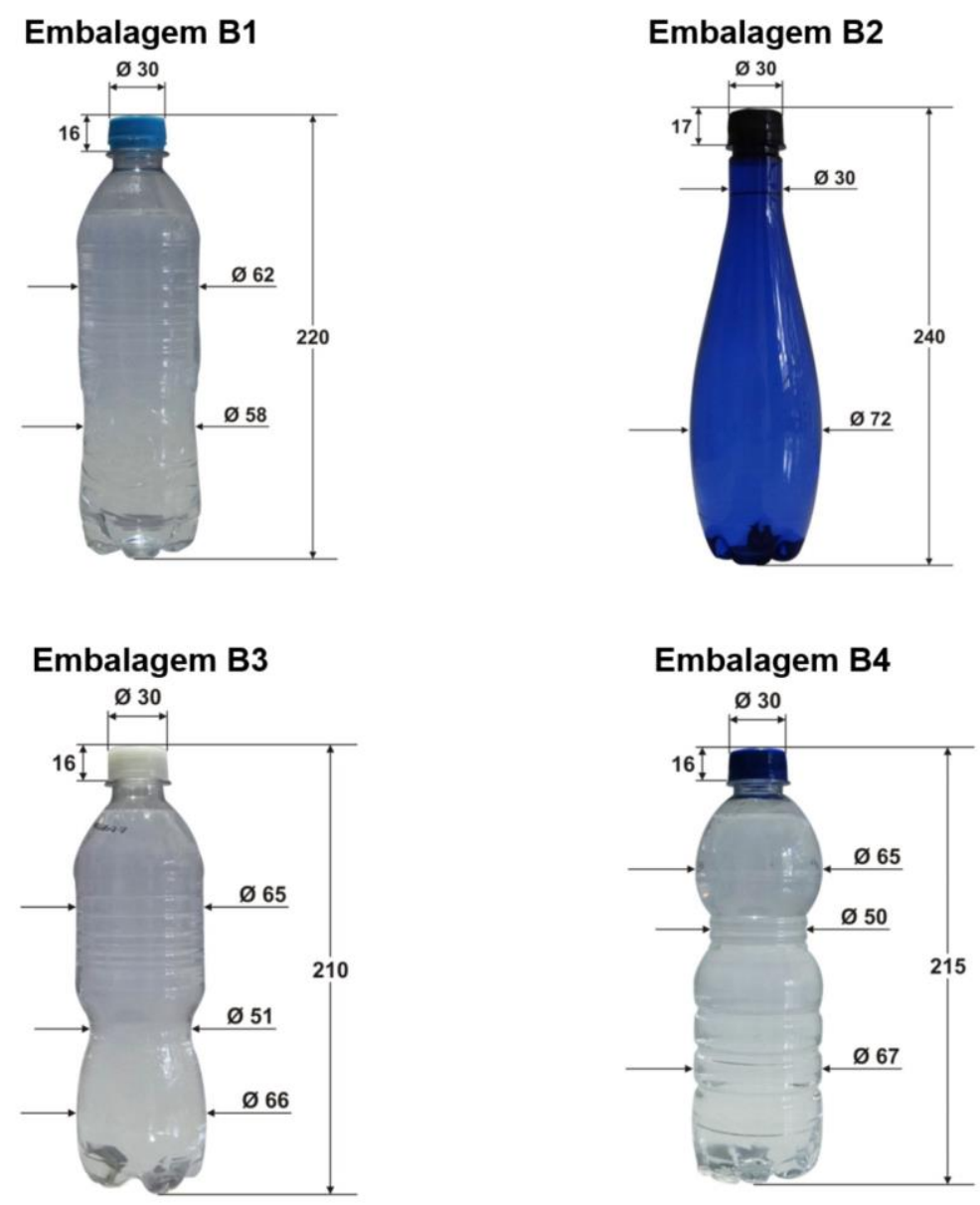

\section{Embalagem B5}

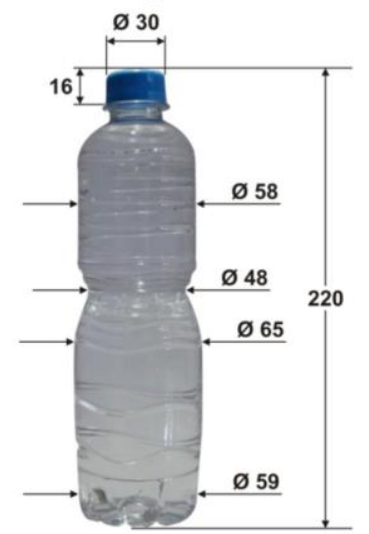

Figura 03: Embalagens utilizadas no Brasil (todas as dimensões estão em milímetros) 

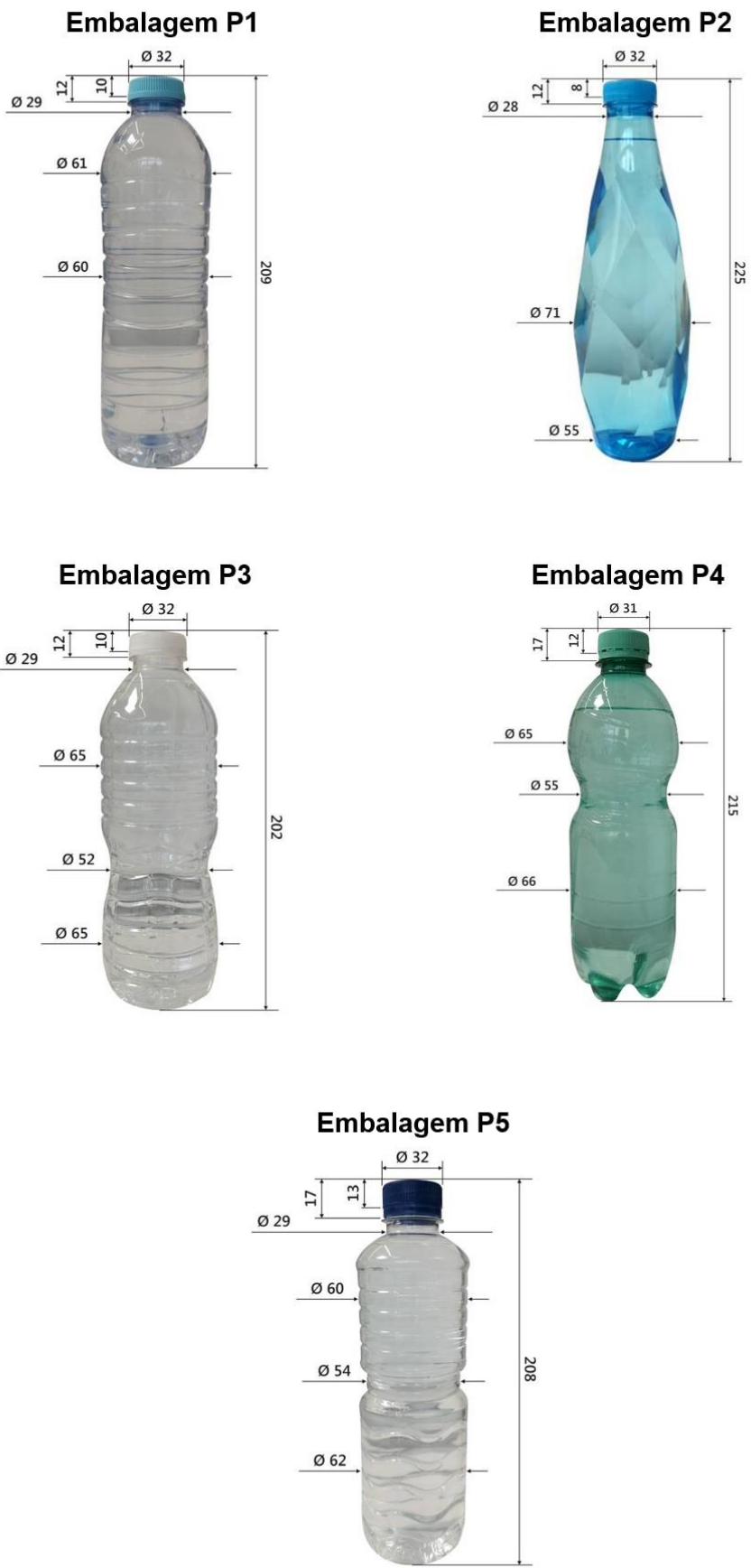

Figura 04: Embalagens utilizadas em Portugal (todas as dimensões estão em milímetros)

- Bancadas com Altura Regulável. Utilizadas para suporte das embalagens durante a realização da atividade, com regulação de altura $(300-930 \mathrm{~mm})$ para adequação às condições antropométricas dos participantes, possibilitando isolar o fator "estatura do participante" nos resultados do estudo.

- Câmera Digital (PowerShot SX520 HS - Canon®). Utilizada para a gravação dos testes para posterior análise das interações com as embalagens. 


\section{Procedimentos}

O início do teste se dava com o convite ao participante, apresentando ao mesmo os objetivos e propósitos do estudo. Uma vez concordando com a participação, era apresentado o TCLE, o qual era lido e preenchido pelo participante, seguido do Protocolo de Identificação.

Na sequência, o sujeito se colocava em pé frente à bancada, com o braço em posição natural e o cotovelo a $90^{\circ} \mathrm{e}$, desta forma, a bancada era ajustada de tal maneira que a altura do centro da embalagem, que estava colocada sobre a mesma, coincidisse com a altura do centro da palma da mão.

Apenas uma única embalagem era posicionada na bancada próxima ao indivíduo. Então, o participante era instruído que deveria pegar a embalagem, abri-la, e por fim, colocá-la novamente sobre a bancada. Somente após esta instrução, o participante realizava a atividade, de modo subsequente para cada uma das demais embalagens, as quais eram apresentadas em sequência randomizada. Toda a atividade foi registrada em vídeo, permitindo avaliar todas as condições de preensão empregadas pelos participantes para a completude da mesma.

\section{Análise dos dados}

Todos os dados coletados foram tabulados e organizados em planilhas eletrônicas. Foram agrupados de acordo com as variáveis estudadas (gênero, embalagem e faixa etária). A estatística descritiva foi aplicada para a obtenção de média, desvio padrão e frequência para todos os conjuntos de dados.

\section{Resultados}

No Brasil, a média de idade para os jovens do gênero masculino foi de 25,95 anos (d.p. $\pm 5,32$ ); e para o gênero feminino, a média foi de 24,80 anos (d.p. $\pm 3,50$ ). Os homens de 30 a 55 anos tiveram uma média de idade igual a 45,10 anos (d.p. $\pm 7,22$ ), enquanto para as mulheres, a média foi de 41,90 anos (d.p. $\pm 7,52$ ). Por fim, os seniores obtiveram uma média de idade igual a 66,05 anos (d.p. $\pm 5,83$ ) para os homens; e 63,15 anos (d.p. $\pm 6,07$ ) para as mulheres. Já em Portugal, a média de idade para os jovens do gênero masculino foi de 22,30 anos (d.p. $\pm 3,40$ ); e para o gênero feminino, a média foi de 23,40 anos (d.p. $\pm 3,53$ ). Os homens de 30 a 55 anos tiveram uma média de idade igual a 39,25 anos (d.p. $\pm 7,74$ ), enquanto para as mulheres, a média foi de 42,05 anos (d.p. $\pm 6,26)$. Por fim, os seniores obtiveram uma média de idade igual a 72,70 anos (d.p. $\pm 11,10$ ) para os homens; e 72,90 anos (d.p. $\pm 10,46$ ) para as mulheres.

\section{Jovens - 18 a 19 anos}

As frequências com que cada affordance foi utilizada pelos jovens brasileiros durante a abertura das embalagens podem ser observadas na Figura 05. 

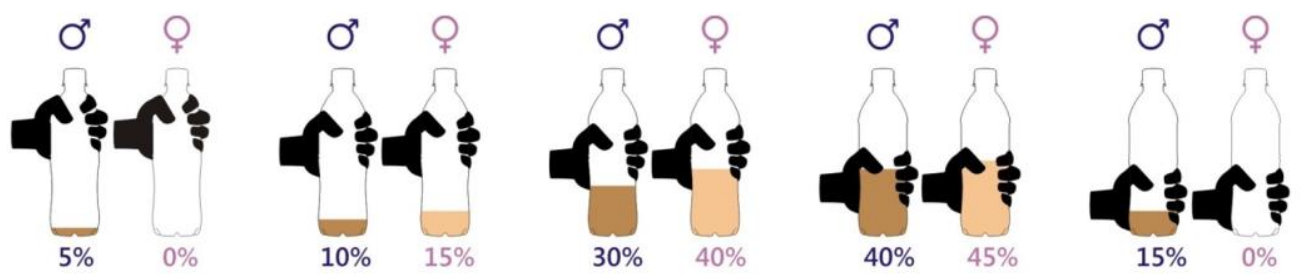

B1
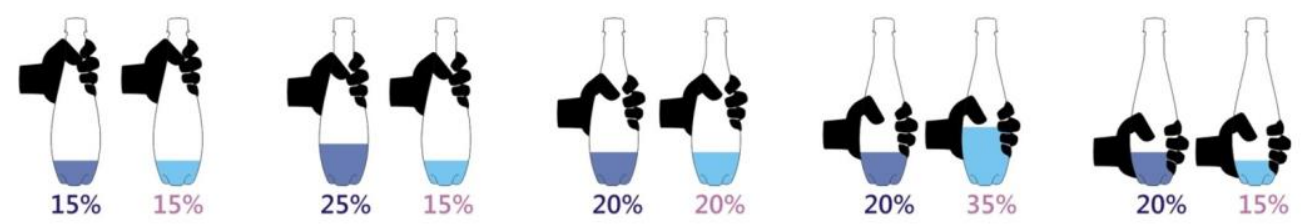

B2

B3
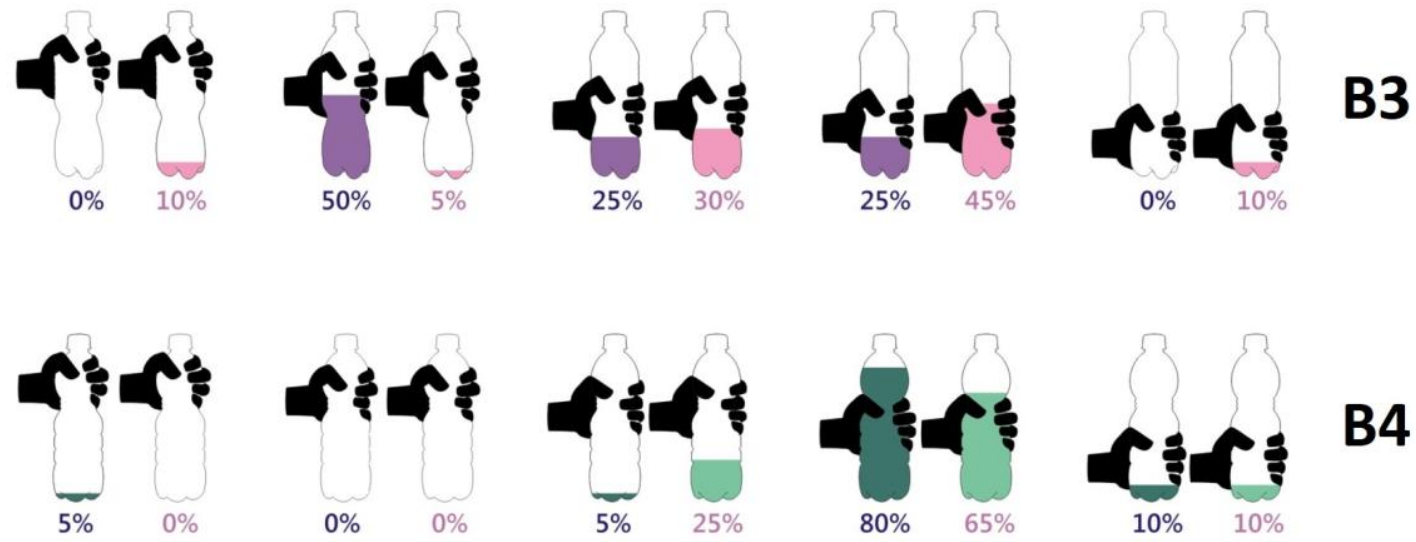

B4
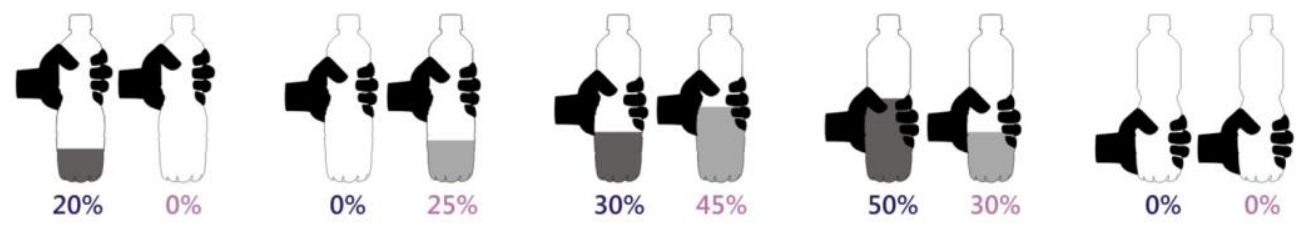

B5

Figura 05: Frequência que cada affordance foi utilizada pelos jovens brasileiros na abertura das embalagens

Os resultados apontam que, para a embalagem B1, tanto para os homens, quanto para as mulheres, a preensão mais utilizada ocorreu nas regiões centro-inferior, seguida das regiões centrais e centro superior. Já para a embalagem B2, de maneira geral, a preensão na região centroinferior foi a mais utilizada, seguida das preensões nas regiões central e centro-superior. Ao analisar os gêneros separadamente para esta embalagem, nota-se que para os homens, a preensão na região centro-superior foi mais frequente, enquanto para as mulheres a preensão mais utilizada foi na região centro-inferior. Com relação à embalagem B3, no geral, as preensões com o apoio na cintura do dedo médio, anelar e mínimo foram as mais utilizadas. Para os participantes do gênero masculino o maior destaque foi para a preensão com apoio do dedo mínimo, ao passo que para o gênero feminino o destaque foi para a preensão com apoio do dedo médio na cintura. Para a embalagem B4, em todos os casos, a preensão mais utilizada ocorreu com apoio do dedo indicador na cintura. $\mathrm{Na}$ embalagem $\mathrm{B}$, as preensões mais utilizadas foram aquelas com apoio 
do dedo indicador e médio na cintura, sendo que para os homens o destaque foi o apoio do dedo indicador e para as mulheres o destaque foi o apoio do dedo médio.

As frequências com que cada affordance foi utilizada pelos jovens portugueses na abertura das embalagens podem ser observadas na Figura 06.

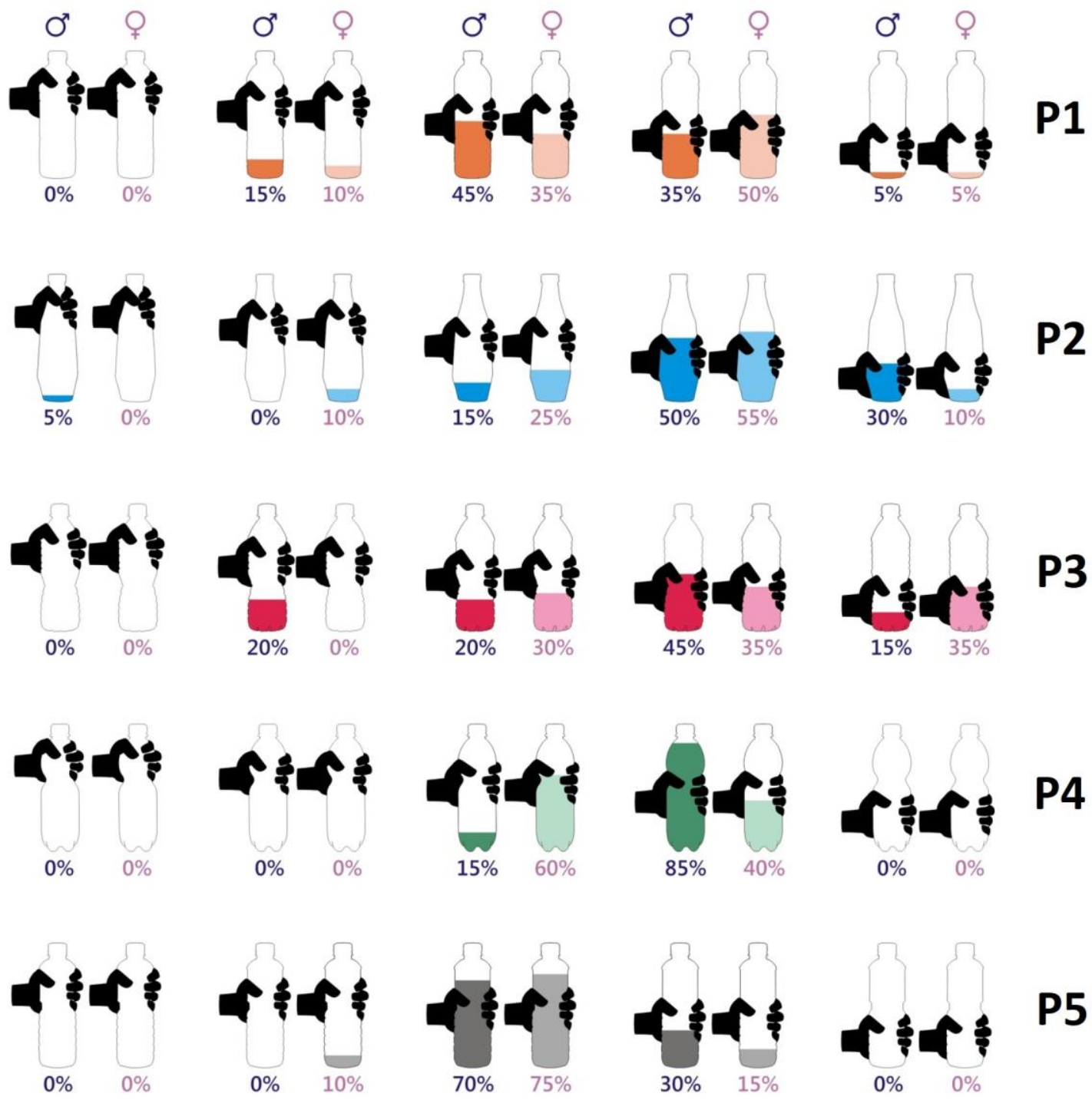

Figura 06: Frequência que cada affordance foi utilizada pelos jovens portugueses na abertura das embalagens

A partir destes resultados, é possível observar que na embalagem P1, as preensões mais frequentes foram nas regiões central e centro-inferior, sendo que os participantes do gênero masculino se utilizaram mais da preensão na região central e os do gênero feminino, a preensão na região centro-inferior. Para a embalagem $\mathrm{P} 2$, em todos os casos a preensão mais utilizada foi na região centro-inferior, enquanto na embalagem P3 a preensão mais frequente foi com o apoio do dedo médio na cintura. Com relação à embalagem $\mathrm{P} 4$, as preensões mais frequentes ocorreram com apoio dos dedos indicador (especialmente entre os homens) e médio (especialmente entre as 
mulheres) na cintura. Na embalagem $\mathrm{P}$, em todos os casos, a preensão com o apoio do dedo médio foi a mais utilizada.

\section{Adultos - 30 a 55 anos}

As frequências com que cada affordance foi utilizada pelos adultos brasileiros na abertura das embalagens podem ser observadas na Figura 07.
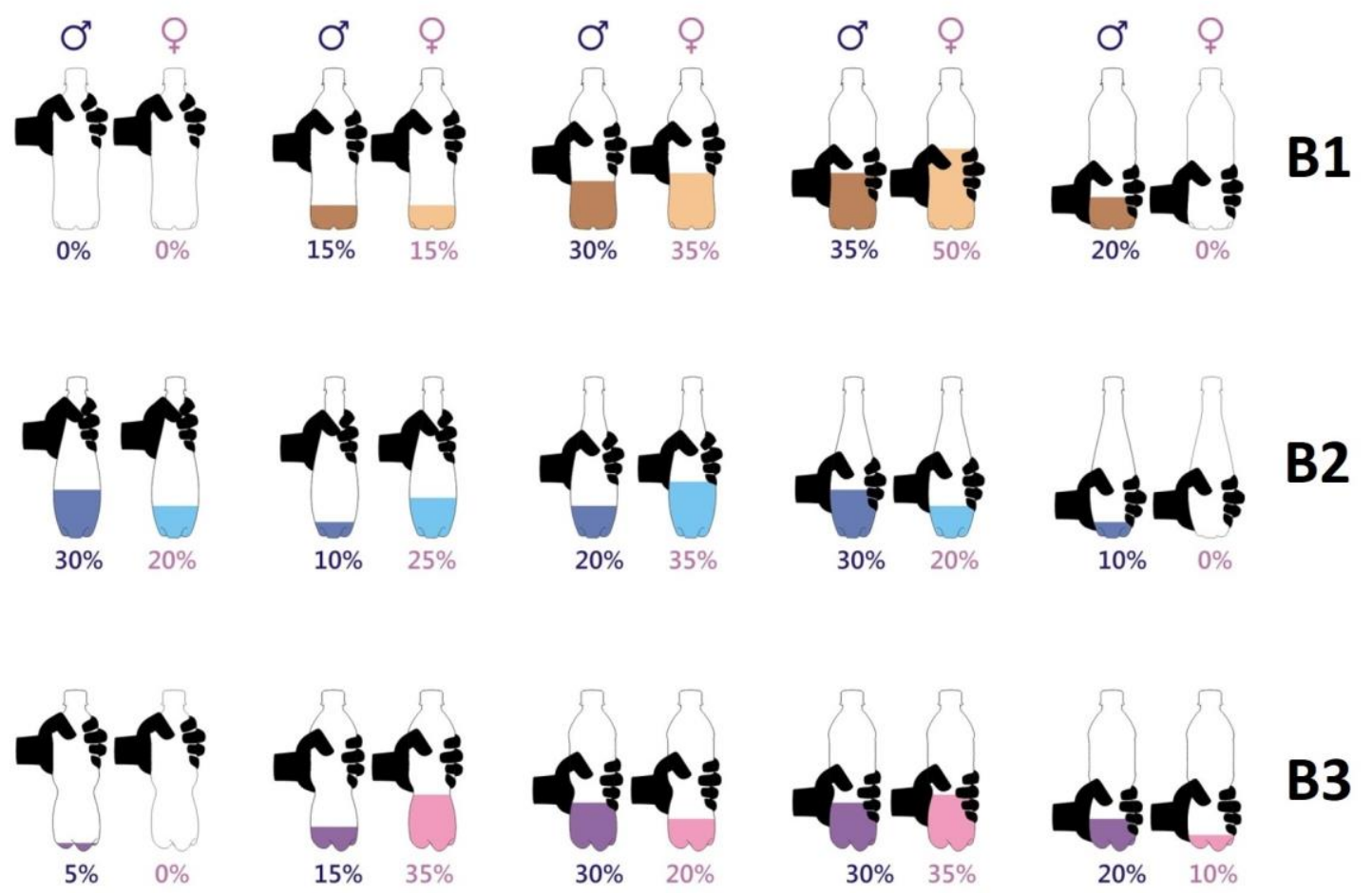

B3
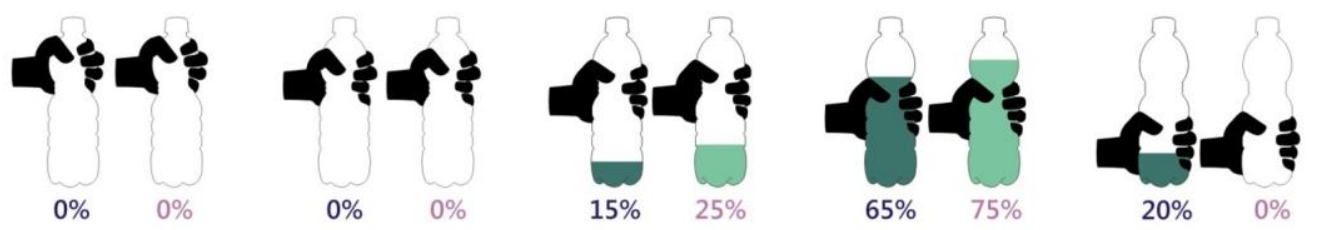

B4
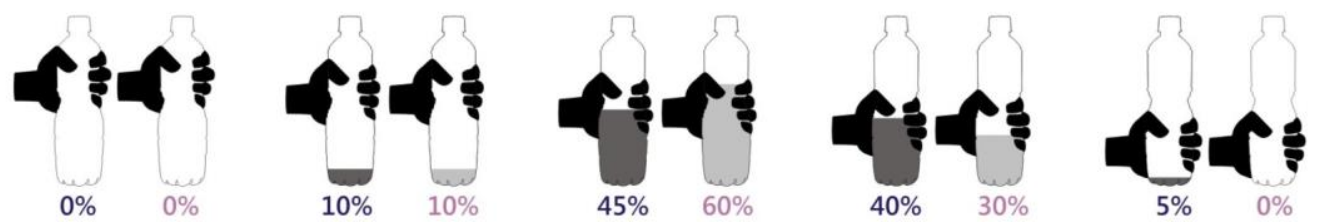

B5

Figura 07: Frequência que cada affordance foi utilizada pelos adultos brasileiros na abertura das embalagens

Observa-se que para a embalagem B1, tanto para os homens, quanto para as mulheres, a preensão mais frequente ocorreu na região centro-inferior. Já para a embalagem B2, destacam-se 
as preensões na região superior e centro-inferior para os homens e da preensão na região central para as mulheres. Para a embalagem B3, a preensão com o apoio do dedo médio na cintura da embalagem ocorreu com mais frequência, ao passo que para a embalagem B4, a preensão mais frequente foi aquela como apoio do dedo indicador na cintura. E, com relação a embalagem B5, o maior destaque é a preensão com o apoio do dedo médio na cintura.

As frequências com que cada affordance foi utilizada pelos adultos portugueses na abertura das embalagens podem ser observadas na Figura 08.
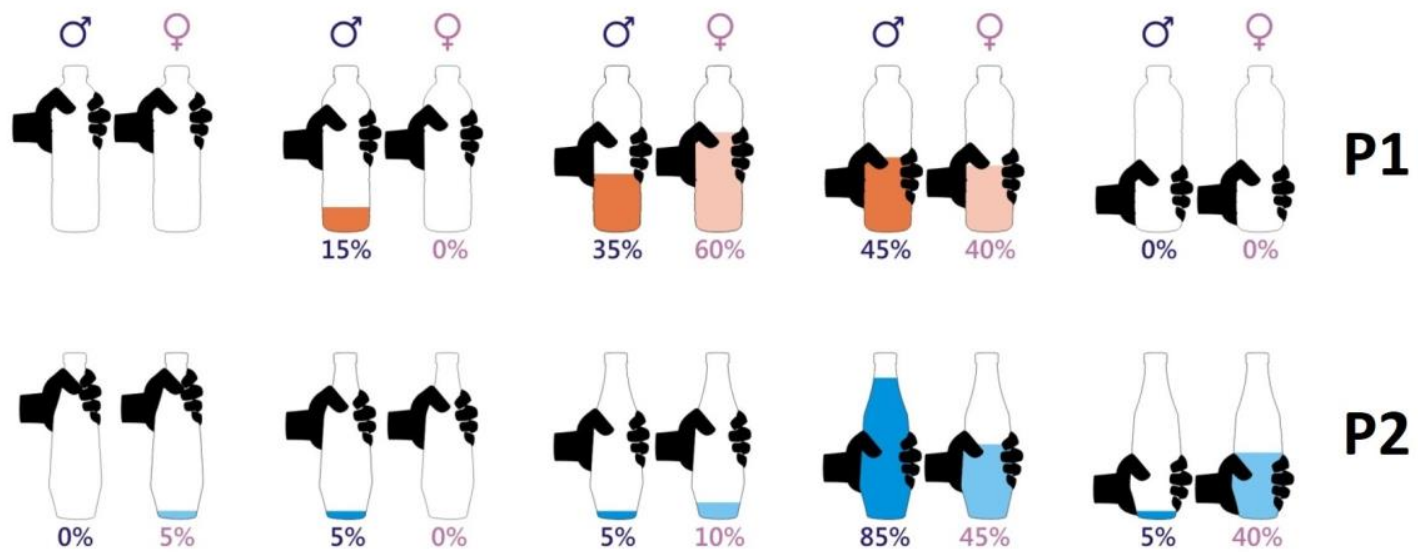

P2
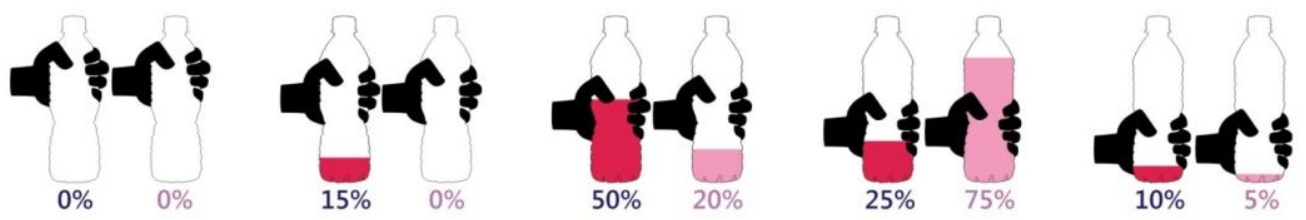

P3
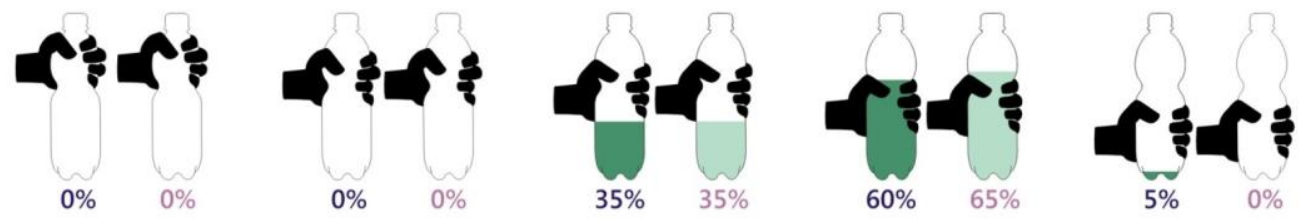

P4
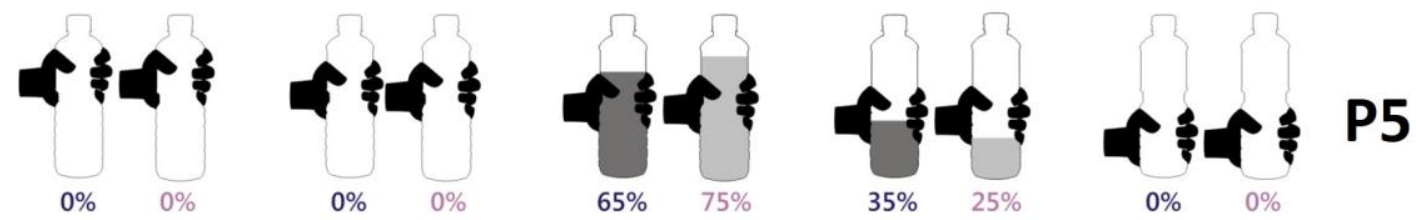

Figura 08: Frequência que cada affordance foi utilizada pelos adultos portugueses na abertura das embalagens

Observa-se que, para a embalagem P1, os homens utilizaram-se mais da preensão na região centro inferior, enquanto as mulheres utilizaram mais da pega preensão na região central. Já para a embalagem P2, em todos os casos, a preensão de maior frequência ocorreu na região centroinferior. Com relação à embalagem P3, a preensão mais frequente para o gênero masculino ocorreu com o apoio do dedo anelar na cintura; e para o gênero feminino, o destaque foi para a preensão com apoio do dedo médio na cintura. Para a embalagem P4, a pega mais utilizada foi o 
apoio do dedo indicador na cintura, enquanto na embalagem P5, a pega com apoio do dedo médio na cintura foi a mais frequente.

\section{Seniores - acima de 55 anos}

As frequências com que cada affordance foi utilizada pelos seniores brasileiros na abertura das embalagens podem ser observadas na Figura 09.

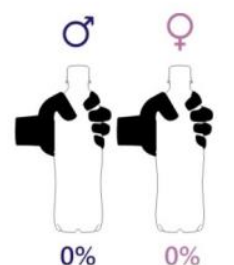

$0 \%$
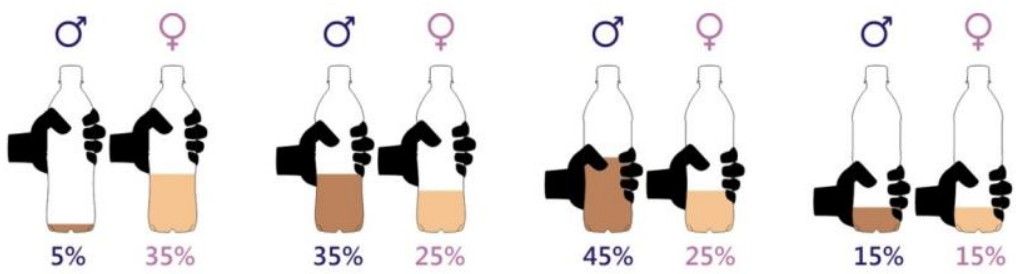

B1
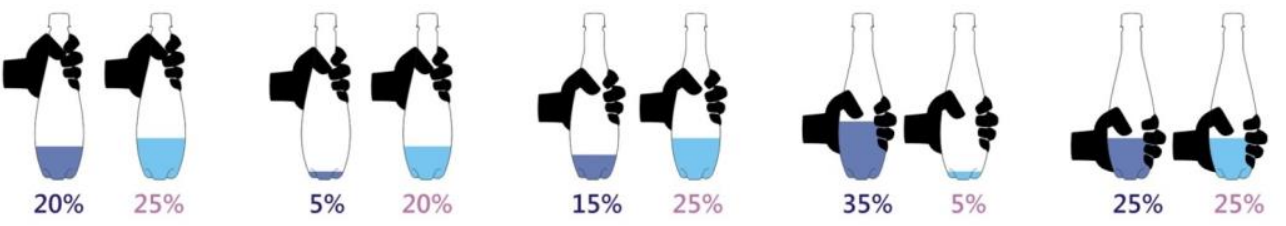

B2
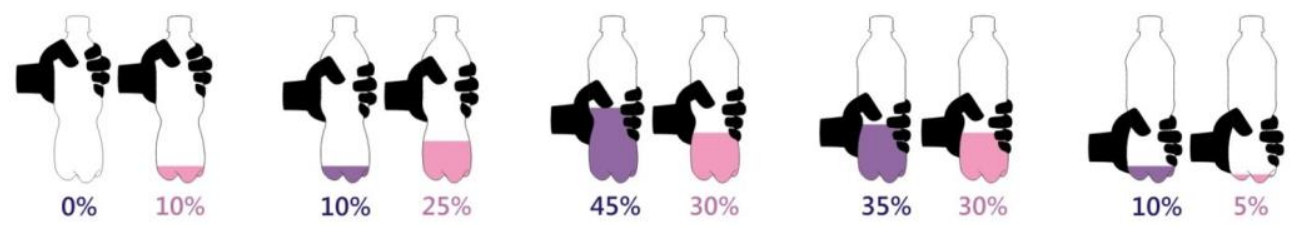

B3
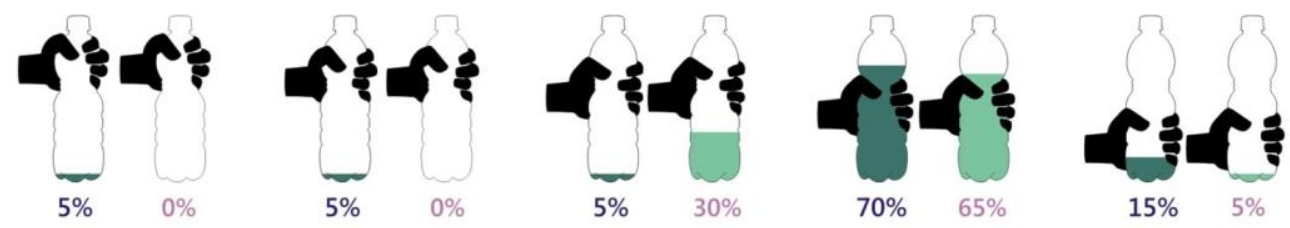

B4
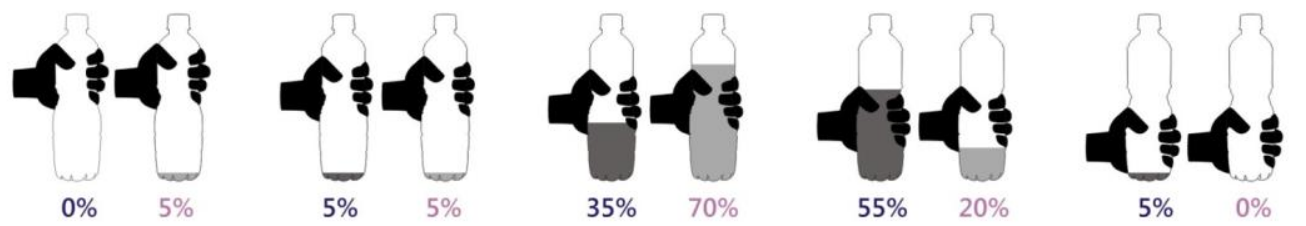

B5

Figura 09: Frequência que cada affordance foi utilizada pelos seniores brasileiros na abertura das embalagens

Observa-se que para a embalagem B1, de maneira geral, as preensões nas regiões centroinferior, central e centro-superior foram as mais utilizadas. Ao analisar os gêneros separadamente 
para esta embalagem, nota-se que para os homens, a preensão na região centro-inferior foi a mais frequente; enquanto que para as mulheres a preensão mais utilizada foi na região centro-superior. $\mathrm{Na}$ embalagem B2, as pegas variaram, com destaque da preensão na região centro-inferior para os homens, ao passo que as preensões nas regiões superior, central e inferior foram igualmente utilizadas pelas mulheres. Em se tratando da embalagem B3, nota-se que, em todos os casos, a preensão mais frequente ocorreu com o apoio do dedo anelar na cintura. Já para a embalagem B4, o maior destaque foi da preensão com o apoio do dedo indicador na cintura. E com relação à embalagem B5, os participantes do gênero masculino utilizaram-se mais da preensão com apoio do dedo indicador na cintura, enquanto que para as mulheres, a maior frequência foi a preensão com apoio do dedo médio na cintura.

As frequências com que cada affordance foi utilizada pelos seniores portugueses na abertura das embalagens podem ser observadas na Figura 10.
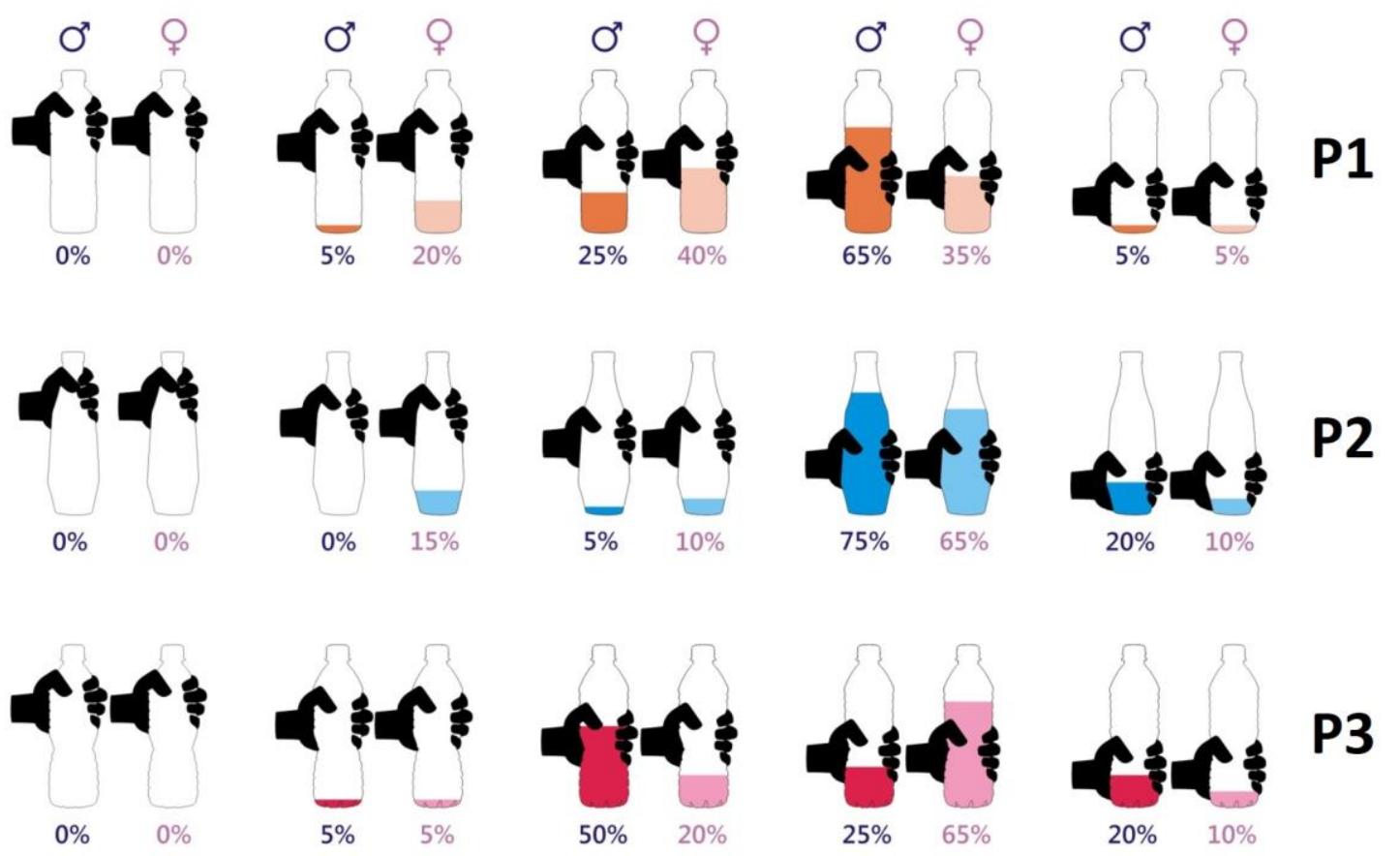

P3
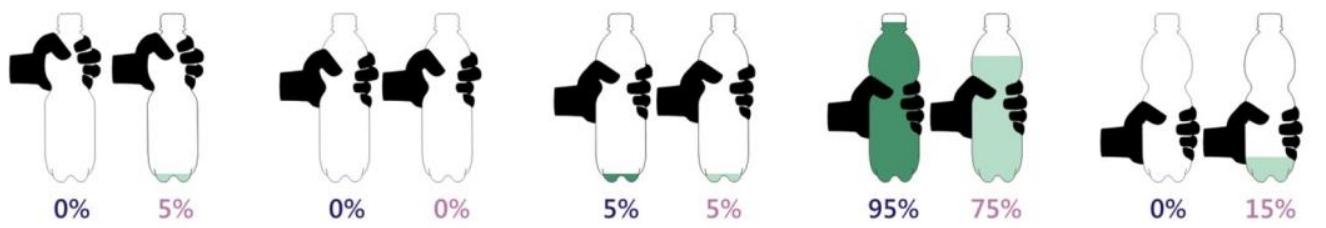

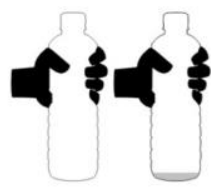

$0 \% \quad 5 \%$

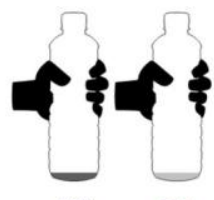

$5 \% \quad 5 \%$

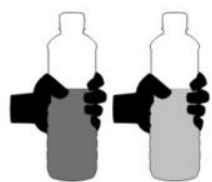

$55 \% \quad 55 \%$

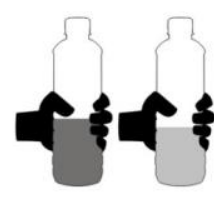

$40 \% \quad 35 \%$

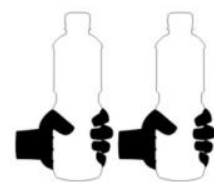

P5

Figura 10: Frequência que cada affordance foi utilizada pelos seniores portugueses na abertura das embalagens 
Os resultados mostram que, para a embalagem $\mathrm{P} 1$, a preensão mais frequente para os homens foi na região centro-inferior, enquanto para as mulheres foi a preensão na região central. $\mathrm{Na}$ embalagem P2, a preensão mais utilizada foi na região centro-inferior para todos os casos. Com relação à embalagem P3, a preensão com apoio do dedo anelar na cintura foi a mais frequente para o gênero masculino, ao passo que a preensão com apoio do dedo médio na cintura foi a mais recorrente para o gênero feminino. Na embalagem $\mathrm{P} 4$, a preensão mais observada foi com o apoio do dedo indicador na cintura, enquanto na embalagem P5, o uso mais frequente foi da preensão com apoio do dedo médio na cintura.

\section{Discussão}

Compreender as affordances pode ser uma parte importante para os estudos sobre as atividades motoras de manipulação, visto que diferentes formatos de um mesmo objeto podem influenciar o posicionamento da preensão das mãos; e isto pode ser uma importante contribuição para o ergodesign de produtos. O presente estudo teve como propósito analisar como se dá o posicionamento da preensão das mãos no objeto, durante a abertura de embalagens de água mineral com diferentes formatos; e como essa ação é influenciada pelas affordances.

De maneira geral, os resultados apontam expressiva semelhança entre as affordances empregadas pela amostra de participantes Brasileiros e Portugueses. Entre esses dois grupos há intensa relação cultural, o que pode corroborar com a ideia de que as affordances recebem influência da cultura dos indivíduos. Isto é explicado por Kitayama et al. (2006), ao demonstrarem que entre grupos culturais distintos, o emprego das affordances pode ser influenciado por esta diferença.

Para a grande maioria das embalagens (B1, P1, P2, B4, P4, B5 e P5), notou-se que a geometria desses produtos e o centro de massa foram os fatores determinantes para a escolha dos indivíduos posicionarem suas mãos durante a abertura das embalagens, ou seja, os sujeitos posicionaram suas mãos no centro de massa desses produtos buscando o melhor encaixe dos dedos de acordo com a forma das embalagens. Isto foi observado por outros estudos, como os de Baud-Bovy e Soechting (2001), Lederman e Wing (2003), Lukos et al. (2007), Lukos et al. (2008) e Sartori et al. (2011), os quais corroboram com a hipótese de que a forma dos objetos pode ser um fator preponderante para os usuários empregarem diferentes affordances nos produtos.

Para a embalagem B2, em formato de gota, não houve uma padronização com relação ao local da preensão, ou seja, os indivíduos utilizaram-se de diferentes affordances para segurar este produto, não havendo uma que tenha sido mais recorrente. Provavelmente isto ocorreu, pois a grande maioria das embalagens de água mineral apresenta um formato padrão caracterizado como cilíndrico, com pequenos sulcos e cinturas transversais. A alteração abrupta da configuração de um produto, provavelmente induzirá os usuários a buscarem outras affordances para a interação com o mesmo.

Com relação às embalagens $\mathrm{B} 3$ e P3, estas foram as únicas que apresentaram diferenças entre homens e mulheres. Os participantes do gênero masculino parecem preferir uma posição mais central com o apoio do dedo anelar na cintura, seguindo o princípio do centro de massa já 
observado por Lukos et al. (2007), Lukos et al. (2008) e Sartori et al. (2011). Em contrapartida, o gênero feminino pareceu preferir a posição centro-inferior com o apoio do dedo médio na cintura, visto que este dedo trabalhando em oposição ao polegar gera mais precisão para a realização da tarefa (SARTORI et al., 2011).

Lederman e Wing (2003) apontam que os indivíduos buscam um ponto de simetria nos objetos para poder segurá-los, porém para as embalagens B2, B3 e P3 parece haver uma maior dificuldade por parte dos participantes em encontrar uma simetria nestes produtos, uma vez que na embalagem com formato de gota (B2) o peso maior do objeto está na região inferior e as embalagens com a cintura abaixo do centro (B3 e P3) acabam transmitindo uma ideia de desequilíbrio e instabilidade no formato do objeto, pois a concavidade é muito baixa e o peso maior parece estar na região superior da embalagem, gerando inconformidade na preensão de tais embalagens.

Além disso, cabe ressaltar que as regiões côncavas das embalagens possibilitam boas affordances e auxiliam na manipulação dos objetos, como já observado por Sartori et al. (2011). No entanto, o posicionamento da cintura abaixo da região central da embalagem parece não ser uma boa opção.

De maneira geral, o presente estudo mostrou que a manipulação efetiva dos produtos depende da capacidade do indivíduo de perceber as affordances nos objetos. Especificamente, os resultados, em conformidade com Mon-Williams e Bingham (2011), Sartori et al. (2011) e Crajé et al. (2011), sugerem que quando os sujeitos podem escolher como manipular um objeto a partir de várias affordances disponíveis, eles utilizam-se de mecanismos funcionais para controlar a preensão por meio da seleção do melhor posicionamento das mãos.

\section{Conclusão}

A análise de affordances é um componente importante para a investigação de tarefas motoras que envolvem a manipulação de produtos, pois são as affordances que determinam a estrutura das ações que serão realizadas pelos usuários.

No presente estudo, foi possível observar que regiões côncavas nas embalagens, como as cinturas, podem auxiliar a manipulação desses produtos, porém quando estão localizadas abaixo da região central, acabam por transmitir uma ideia de desequilíbrio e instabilidade no formato do objeto, podendo dificultar a percepção das melhores affordances e, consequentemente, geram insatisfação no uso de tais produtos.

Destaca-se também que os objetos podem ser manipulados de formas diferentes, dependendo do objetivo final e das intenções de quem realizará a ação; portanto são sugeridos estudos adicionais que venham investigar a natureza das affordances dos objetos e sua relação com outros fatores que influenciam a interação entre usuários e produtos.

Por fim, estudos de natureza experimental e aplicada, que levam em consideração as affordances, podem trazer novos benefícios para a pesquisa científica na subárea do Design de Produto. 


\section{Agradecimentos}

Este estudo foi desenvolvido com apoio da FAPESP - Fundação de Amparo à Pesquisa do Estado de São Paulo (Processos 2014/23953-6 e 2016/22197-9), CNPq - Conselho Nacional de Desenvolvimento Científico e Tecnológico (Processos 403220/2016-5 e 304619/2018-3) e CIAUD - Centro de Investigação em Arquitetura, Urbanismo e Design.

\section{Referências}

ABERGO. Norma ERG BR 1002 - Código de Deontologia do Ergonomista Certificado. Associação Brasileira de Ergonomia, 2003.

ANSUINI, C.; SANTELLO, M.; MASSACCESI, S.; CASTIELLO, U. Effects of end-goal on hand shaping. Journal of Neurophysiology, v. 95, p. 2456-2465, 2006. DOI: https://doi.org/10.1152/jn.01107.2005

ANSUINI, C.; GIOSA, L.; TURELLA, L.; ALTOÈ, G.; CASTIELLO, U. An object for an action, the same object for other actions: eVects on hand shaping. Experimental Brain Research, v. 185, p. 111-119, 2008. DOI: https://doi.org/10.1007/s00221-007-1136-4

BAUD-BOVY, G.; SOECHTING, J.F. Two virtual fingers in the control of the tripod grasp. Journal of Neurophysiology, v. 86, p. 604-615, 2001. DOI: https://doi.org/10.1152/jn.2001.86.2.604

BOOTSMA, R. J.; MARTENIUK, R. G.; MACKENZIE, C. L.; ZAAL, F. T. J. M. The speedaccuracy trade off in manual prehension: effects of movement amplitude, object size and object width on kinematic characteristics. Experimental Brain Research, v. 98, p. 535-541, 1994. DOI: https://doi.org/10.1007/BF00233990

CASELLA, G.; BERGER, R.L. Statistical Inference. Second Edition. New York: Duxbury Thomsom Learning, 2002. 660p.

CASTIELLO, U. Grasping a fruit: selection for action. Journal of Experimental Psychology: Human Perception and Performance, v. 22, p. 582-603, 1996. DOI: https://doi.org/10.1037/0096-1523.22.3.582

CASTIELLO, U. Mechanisms of selection for the control of hand action. Trends in Cognitive Sciences, v. 3, p. 264-271, 1999. DOI: https://doi.org/10.1016/S1364-6613(99)01346-7

COHEN, R.G.; ROSENBAUM, D.A. Where grasps are made reveals how grasps are planned: generation and recall of motor plans. Experimental Brain Research, v. 157, p. 486-495, 2004. DOI: https://doi.org/10.1007/s00221-004-1862-9

CRAIGHERO, L.; FADIGA, L.; RIZZOLATTI, G.; UMILTÀ, C. Action for perception: A motor-visual attentional effect. Journal of Experimental Psychology: Human Perception and Performance, v. 25, p. 1673-1692, 1999. DOI: https://doi.org/10.1037/00961523.25.6.1673

CRAJÉ, C.; LUKOS, J. R.; ANSUINI, C.; GORDON, A. M. SANTELLO, M. The effects of task and content on digit placement on a bottle. Experimental Brain Research, v. 212, p. 119-124, 2011. DOI: https://doi.org/10.1007/s00221-011-2704-1

ELLIS, R.; TUCKER, M. Micro-affordance: The potentiation of components of action by seen objects. British Journal of Psychology, v. 91, p. 451-471, 2000. DOI: https://doi.org/10.1348/000712600161934

GIBSON, J. J. The Ecological Approach to Visual Perception - Classic Edition. New York: Psychology Press, 2015. 315p. 
GIBSON, J. J. The theory of affordances. In: Shaw, R.; Bransford, J. (Eds.). Perceiving, acting and knowing. Hillsdale, NJ: Erlbaum, pp. 67-82, 1977.

GORDON, A. M.; FORSSBERG, H.; JOHANSSON, R. S.; WESTLING, G. Visual size cues in the programming of manipulative forces during precision grip. Experimental Brain Research, v. 83, p. 477-482, 1991. DOI: https://doi.org/10.1007/BF00229824

JEANNEROD, M. Intersegmental coordination during reaching at natural visual objects. In: Long, J.; Baddeley, A. (eds) Attention and performance IX. Erlbaum, Hillsdale, pp. 153$168,1981$.

JOHANSSON, R. S.; WESTLING, G. Coordinated isometric muscle commands adequately and erroneously programmed for the weight during lifting task with precision grip. Experimental Brain Research, v. 71, p. 59-71, 1988. DOI: https://doi.org/10.1007/BF00247522

KAPANDJI, A.I. Fisiologia Articular - Ombro, Cotovelo, Prono-supinação, Punho, Mão. Rio de Janeiro: Guanabara Koogan. 2007. 374p.

KITAYAMA, S.; MESQUITA, B.; KARASAWA, M. Cultural affordances and emotional experience: Socially engaging and disengaging emotions in Japan and the United States. Journal of Personality and Social Psychology, v. 91, p. 890-903, 2006. DOI: https://doi.org/10.1037/0022-3514.91.5.890

LEDERMAN, S. J.; WING, A.M. Perceptual judgement, grasp point selection and object symmetry. Experimental Brain Research, v. 152, p. 156-165, 2003. DOI: https://doi.org/10.1007/s00221-003-1522-5

LOMBARDO, T. J. The Reciprocity of Perceiver and Environment: The Evolution of James J. Gibson's Ecological Psychology. New Jersey: Lawrence Erlbaum Associates, 1987. 396p.

LUKOS, J.; ANSUINI, C.; SANTELLO, M. Choice of contact points during multidigit grasping: eVect of predictability of object center of mass location. The Journal of Neuroscience, v. 27, p. 3894-3903, 2007. DOI: https://doi.org/10.1523/JNEUROSCI.469306.2007

LUKOS, J.; ANSUINI, C.; SANTELLO, M. Anticipatory control of grasping: independence of sensorimotor memories for kinematics and kinetics. The Journal of Neuroscience, v. 28, n. 48, p. 12765-12774, 2008. DOI: https://doi.org/10.1523/JNEUROSCI.4335-08.2008

MARK, L.S.; NEMETH, K.; GARDNER, D.; DAINOFF, M.J.; DUFFY, M.; GRANDT, K. Postural dynamics and the preferred critical boundary for visually-guided reaching. Journal of Experimental Psychology: Human Perception and Performance, v. 23, p. 1-15, 1997. DOI: https://doi.org/10.1037/0096-1523.23.5.1365

MASON, C.R.; GOMEZ, J.E.; EBNER, T.J. Hand synergies during reach-to-grasp. Journal of Neurophysiology, v. 86, p. 2896-2910, 2001. DOI: https://doi.org/10.1152/jn.2001.86.6.2896

MICHAELS, C. F. S-R. Affordances: Four Points of Debate. Ecological Psychology, v.15, n.2, p.135-48, 2003. DOI: https://doi.org/10.1207/S15326969ECO1502_3

MON-WILLIAMS, M.; BINGHAM, G.P. Discovering affordances that determine the spatial structure of reach-to-grasp movements. Experimental Brain Research, v. 211, p. 145-60, 2011. DOI: https://doi.org/10.1007/s00221-011-2659-2

PAULIGNAN, Y.; FRAK, V. G.; TONI, I.; JEANNEROD, M. Influence of object position and size on human prehension movements. Experimental Brain Research, v. 114, p. 226234, 1997. DOI: https://doi.org/10.1007/PL00005631 
PHILLIPS, J. C.; WARD, R. S-R correspondence effects of irrelevant visual affordance: Time course and specificity of response activation. Visual Cognition, v. 9, p. 540-558, 2002. DOI: https://doi.org/10.1080/13506280143000575

REED, E. S. James J. Gibson and the Psychology of Perception. New Haven: Yale University Press, 1988. 348p.

SANTELLO, M.; SOECHTING, J.F. Gradual molding to the object contours. Journal of Neurophysiology, v. 79, p. 1307-1320, 1998. DOI: https://doi.org/10.1152/jn.1998.79.3.1307

SARTORI, L.; STRAULINO, E.; CASTIELLO, U. How Objects Are Grasped: The Interplay between Affordances and End-Goals. PLOS ONE, v.6, n. 9, 2011. DOI: https://doi.org/10.1371/journal.pone.0025203

SAVELSBERGH, G. J. P.; STEENBERGEN, B.; VAN DER KAMP, J. The role of fragility information in the guidance of the precision grip. Human Movement Science, v. 15, p. 115127, 1996. DOI: https://doi.org/10.1016/0167-9457(95)00039-9

SMEETS, J. B. J.; BRENNER, E. A new view on grasping. Motor Control, v. 3, p. 237-271, 1999. DOI: https://doi.org/10.1123/mcj.3.3.237

TUCKER, M.; ELLIS, R. On the relations between seen objects and components of potential actions. Journal of Experimental Psychology: Human Perception and Performance, v. 24, p. 830-846, 1998. DOI: https://doi.org/10.1080/13506280042000144

TUCKER, M.; ELLIS, R. The potentiation of grasp types during visual object categorization. Visual Cognition, v. 8, p. 769-800, 2001. DOI: https://doi.org/10.1080/13506280042000144

TUCKER, M.; ELLIS, R. Action priming by briefly presented objects. Acta Psychologica, v. 116, p. 185-203, 2004. DOI: https://doi.org/10.1016/j.actpsy.2004.01.004

TURVEY, M. T.; SHAW, R. E.; REED, E. S.; MACE, W. M. Ecological Laws of Perceiving and Acting: in Reply to Fodor and Pylyshyn. Cognition, v.9, n.3, p. 237-304, 1981. DOI: https://doi.org/10.1016/0010-0277(81)90002-0

WARREN JR., W. H. Perceiving affordances: visual guidance of stair climbing. Journal of Experimental Psychology: Human Perception and Performance, v.10, n.5, p. 683-703, 1984. DOI: https://doi.org/10.1037//0096-1523.10.5.683

WEIR, P. L.; MACKENZIE, C. L.; MARTENIUK, R. G.; CARGOE, S. L. Is object texture a constraint on human prehension?: kinematic evidence. Journal of Motor Behavior, v. 23, p. 205-210, 1991a. DOI: https://doi.org/10.1080/00222895.1991.10118363

WEIR, P. L.; MACKENZIE, C. L.; MARTENIUK, R. G.; CARGOE, S. L.; FRASER, M. B. The effects of object weight on the kinematics of prehension. Journal of Motor Behavior, $v$. 23, p. 192-204, 1991b. DOI: https://doi.org/10.1080/00222895.1991.10118362

\section{Sobre os autores}

\section{Gabriel Henrique Cruz Bonfim}

Professor Adjunto A do curso de Design da Faculdade de Arquitetura e Urbanismo e Design (FAUeD) da Universidade Federal de Uberlândia (UFU). Doutor em Design, com ênfase em Ergonomia, pela UNESP e pela ULisboa. Mestre em Design, com ênfase em Ergonomia, e Bacharel em Desenho Industrial, com habilitação em Projeto do Produto, ambos pela UNESP. Dedica-se à pesquisa científica e ao ensino superior, nas disciplinas de Projeto e Ergonomia. ORCID - https://orcid.org/0000-0001-5007-5033. 


\section{Fernando José Carneiro Moreira da Silva}

Professor Catedrático em Design - Faculdade de Arquitetura, ULisboa. Professor com Agregação em Design - Faculdade de Arquitetura, ULisboa. Pós-doutorado em Design Inclusivo pela Universidade de Salford. PhD em Cor em Arquitetura pela Universidade de Salford e pela Universidade Técnica de Lisboa. Presidente do Centro de Investigação em Arquitetura, Urbanismo e Design (CIAUD).

ORCID - https://orcid.org/0000-0002-5972-7787.

\section{Luis Carlos Paschoarelli}

Professor Titular no Departamento de Design da UNESP; Livre-Docente em Design Ergonômico pela UNESP; Pós-doutorado em Ergonomia pela ULISBOA; Doutorado em Engenharia de Produção pela UFSCar. Co-lider no Grupo de Pesquisa: 'Design Ergonômico: Projeto e Interfaces'. Lotado no Laboratório de Ergonomia e Interfaces - Departamento de Design. Docente na graduação e na Pós-graduação em Design da UNESP.

ORCID - https://orcid.org/0000-0002-4685-0508. 